\title{
Efektifitas Pemberian Kompres Hangat Terhadap Penurunan Intensitas Dismenorea Pada Remaja Putri Di SMAS Inshafuddin Banda Aceh
}

\author{
Effectiveness Of Giving Warm Compress To Decreasing The Intensity \\ Of Dismenorea In Adolescent Teens In Inshafuddin Banda Aceh Private \\ Vocational School \\ Ulfa Husna Dhirah ${ }^{1}$, Aris Natri Sutami ${ }^{2}$ \\ Universitas Ubudiyah Indonesia, Jln. Alue Naga Desa Tibang, Kecamatan Syiah Kuala, Banda Aceh, Indonesia \\ *Correspoding Author : ulfahusna@uui.ac.id
}

\begin{abstract}
Abstrak
Salah satu tanda seorang perempuan telah memasuki masa pubertas adalah terjadinya menstruasi. Salah satu gangguan yang berhubungan dengan menstruasi yaitu dismenorea. Dismenorea adalah nyeri pada bagian perut, kram, dan sakit punggung bawah sbelum dan selama menstruasi. Di SMAS Inshafuddin Banda Aceh terdapat 37 siswi yang mengalami dismenorea. Untuk mengetahui pengaruh pemberian kompres hangat terhadap penurunan intensitas dismenorea. Rancangan penelitian ini adalah Quasi-Eksperiment dengan desain OneGroup Pre-Post Test Design. Jumlah sampel yang digunakan adalah 37 responden. Alat yang digunakan adalah wong baker face pain Rating Scale untuk mengetahui intensitas nyeri. Analisa yang digunakan adalah wilcoxon karena hasil sebaran data berdistribusi tidak normal dengan hasil $p=0,000$, dengan tingkat kemaknaan $p<0,05$. Nialai rata-rata dismenorea sebelum diberikan kompres hangat adalah 4,70 dan nilai rata-rata setelah pemberian kompres hangat adalah 0,70. Terdapat Penurunan intensitas dismenorea diperoleh nilai $\mathrm{p}=0,000(<\alpha 0,05)$. Ada pengaruh kompres hangat terhadap penurunan intensitas dismenorea. Diharapkan bagi institusi pendidikan Universitas Ubudiyah Indonesia dapat dijadikan sebagai bahan untuk kegiatan proses pembelajaran tentang terapi kompres hangat untuk menurunkan intensitas dismenorea.
\end{abstract}

Kata kunci : Dismenorea, Kompres hangat, Remaja Putri.

\section{Abstract}

One sign that a woman has entered puberty is menstruation. One of the disorders associated with menstruation is dismenorea. Dysmenorrhea is pain in the abdomen, cramps, and lower back pain before and during menstruation. In Inshafuddin High School Banda Aceh there were 37 female students who experienced dysmenorrhea. To determine the effect of giving warm compresses to a decrease in the intensity of dysmenorrhea. The design of this study is Quasi-Experiment with the design of One-Group Pre-Post Test Design. The number of samples used was 37 respondents. The tool used is wong baker face pain Rating Scale to determine the intensity of pain. The analysis used is Wilcoxon because the distribution of data is abnormally distributed with the results of $p=0,000$, with a significance level of $p<0.05$. The average value of dysmenorrhoea before being given a warm compress was 4.70 and the average value after administration of warm compresses was 0.70. There was a decrease in the intensity of dysmenorrhea obtained $p$ value $=0,000(<\alpha$ 0.05). there is an effect of warm compresses on the decrease in the intensity of dysmenorrhea. It is hoped that Ubudiyah University education 
Journal of Healthcare Technology and Medicine Vol. 5 No. 2 Oktober 2019

Universitas Ubudiyah Indonesia

e-ISSN : 2615-109X

institutions in Indonesia can be used as material for the learning process activities on the therapy of warm compresses to reduce the intensity of dysmenorrhoea.

Keywords: Dysmenorrhea, Warm Compress, Young Women.

\section{PENDAHULUAN}

Kesehatan reproduksi remaja putri tidak hanya masalah seksual saja tetapi juga menyangkut segala aspek tentang reproduksinya, terutama untuk remaja putri diantaranya adalah perkembangan seks sekunder, yang meliputi suara lembut, payudara membesar, pembesaran daerah pinggul, dan menarche. Menarche atau terjadinya menstruasi yang pertama kali dialami oleh seorang wanita biasanya terdapat gangguan kram, nyeri dan ketidaknyamanan yang dihubungkan dengan menstruasi disebut dismenorea. Kebanyakan wanita mengalami tingkat kram yang bervariasi, pada beberapa wanita hal itu muncul dalam bentuk rasa tidak nyaman, sedangkan beberapa yang lain menderita rasa sakit yang mampu menghentikan aktifitas sehari - hari (Ema, 2010).

Terapi non-farmakologi yang sering digunakan adalah terapi hangat atau dingin. Salah satu bentuk terapi hangat atau dingin yang sering dilakukan yaitu, dengan pemberian kompres hangat di perut pada penderita dismenorea. Penggunaan kompres hangat di area perut bertujuan untuk melebarkan pembuluh darah sehingga meningkatkan sirkulasi darah ke bagian yang nyeri, menurunkan ketegangan otot sehingga mengurangi nyeri akibat spasme otot atau kekakuan otot (Potter \& Perry, 2010).

Menurut World Health Organization (WHO), didapatkan kejadian sebesar 1.769,425 jiwa (90\%) wanita mengalami dismenorea dan 10\%-15\% diantaranya mengalami dismenorea berat, sehingga mengakibatkan timbulnya keterbatasan aktivitas yang dikeluhkan oleh 15\% remaja perempuan yang mengalami dismenorea.

Di Indonesia angka kejadian dismenorea sebesar 107.673 jiwa (64,25\%), yang terdiri dari 59.671 jiwa $(54,89 \%)$ mengalami dismenorea primer dan 9.496 jiwa $(9,36 \%)$ mengalami dismenorea sekunder. Sedangkan di Aceh di dapatkan 1,07\% sampai 1,31\% dari jumlah penderita dismenorea datang ke bagian kebidanan.

Berdasarkan hasil studi pendahuluan yang telah dilakukan peneliti pada siswi SMAS Inshafuddin Banda Aceh menggunakan teknik wawancara kepada 30 siswi, dimana terdapat 21(70\%) sisiwi yang mengalami dismenorea, $9(30 \%)$ siswi yang lainya yang tidak mengalami dismenorea. 
Journal of Healthcare Technology and Medicine Vol. 5 No. 2 Oktober 2019

Universitas Ubudiyah Indonesia

e-ISSN : 2615-109X

\section{METODE PENELITIAN}

Penelitian ini adalah quasi eksperiment dengan one-group pre-post test design. Populasi dalam penelitian ini adalah seluruh remaja putri yang mengalami dismenorea di kelas I = 13 siswi, kelas II = 10 siswi dan kelas III = 14 siswi, total populasi di SMAS Inshafuddin Banda Aceh berjumlah 37 siswi. Pengambilan sampel dalam penelitian ini dengan cara teknik total Sampling. Instrumen pengumpulan data menggunakan kuesioner dengan cara wawancara dan hasil observasi peneliti. Pengumpulan data ini dilakukan pada tanggal 07 -28 Februari 2019 di SMAS Inshafuddin Banda Aceh. Pengolahan data menggunakan komputer melalui proses editing, coding, tranfering, tabulating. Analisis data dengan tiga data yaitu analisis univariate, bivariate dan multivariate.

\section{HASIL DAN PEMBAHASAN}

\section{Karakteristik responden}

\section{Tabel 1}

Distribusi karakteristik responden di SMAS Inshafuddin Banda Aceh

\begin{tabular}{cccc}
\hline & Karakteristik & Frekuensi (f) & Persentase (\%) \\
\hline Umur & 14 & 2 & 5,4 \\
& 15 & 13 & 35,1 \\
& 16 & 10 & 27,0 \\
& 17 & 12 & 32,4 \\
\cline { 2 - 4 } & Total & 37 & 100,0 \\
\hline \multirow{2}{*}{ Hari } & Karakteristik & Frekuensi (f) & Persentase (\%) \\
merasakan & hari pertama & 30 & 81,1 \\
nyeri & hari kedua & 7 & 18,9 \\
\cline { 2 - 4 } & Total & 37 & 100,0
\end{tabular}

Berdasarkan tabel 1 diketahui data responden berdasarkan karakteristik umurnya, umur 14 tahun sebanyak $2(5,4 \%)$ responden, umur 15 tahun sebanyak $13(35,1 \%)$ responden, umur 16 tahun sebanyak 10 (27\%) responden, kemudian umur 17 tahun sebanyak $12(32,4 \%)$ responden. Karakteristik responden hari mengalami dismenorea sebagian besar pada hari pertama menstruasi sebanyak $30(81,1 \%)$ responden, hari kedua sebanyak $7(18,9 \%)$ responden. 
Journal of Healthcare Technology and Medicine Vol. 5 No. 2 Oktober 2019

Universitas Ubudiyah Indonesia

e-ISSN : 2615-109X

\section{Gambaran intensitas dismenorea sebelum pemberian kompres hangat.}

Berdasarkan hasil penelitian intensitas dismenorea sebelum pemberian kompres hangat diperlihatkan dalam tabel 2.

Tabel 2

Distribusi frekuensi intensitas dismenorea responden sebelum pemberian kompres hangat di SMAS Inshafuddin Banda Aceh

\begin{tabular}{ccc}
\hline & Pretest & \\
\hline Kategorik Nyeri & Frekuensi (f) & Persentase (\%) \\
\hline Nyeri Ringan (1-3) & 11 & $29,7 \%$ \\
Nyeri Sedang (4-6) & 23 & $62,1 \%$ \\
Nyeri Berat (7-10) & 3 & $8,1 \%$ \\
\hline Total & $\mathbf{3 7}$ & $\mathbf{1 0 0 \%}$
\end{tabular}

Berdasarkan tabel 2 dapat diketahui bahwa tingkat intensitas dismenorea sebelum pemberian kompres hangat sebagian besar dalam kategori nyeri sedang skala 4-6 sebanyak $23(62,1 \%)$ responden, dan tingkat nyeri ringan skala 1-3 sebanyak $11(29,7 \%)$ responden, Sedangkan dalam kategori nyeri berat skala 7 sebanyak $3(8,1 \%)$ responden.

\section{Gambaran intensitas dismenorea sesudah pemberian kompres hangat.}

Berdasarkan hasil penelitian intensitas dismenorea sesudah pemberian kompres hangat diperlihatkan dalam tabel 3

Tabel 3

Distribusi frekuensi intensitas dismenorea responden sesudah pemberian kompres hangat di SMAS Inshafuddin Banda Aceh

\begin{tabular}{ccc}
\hline & Posttest & \\
\hline Kategorik Nyeri & Frekuensi (f) & Persentase (\%) \\
\hline Tidak Nyeri (0) & 21 & $56,8 \%$ \\
Nyeri Ringan (1-3) & 15 & $40,5 \%$ \\
Nyeri Sedang (4-6) & 1 & $2,7 \%$ \\
\hline Total & $\mathbf{3 7}$ & $\mathbf{1 0 0 \%}$
\end{tabular}

Berdasarkan tabel 3 dapat diketahui bahwa tingkat intensitas nyeri dismenorea sesudah dilakukan kompres hangat, sebagian besar nyeri responden dalam kategori tidak nyeri skala 0 sebanyak $21(56,8 \%)$ responden, dengan tingkat nyeri ringan skala 1-3 sebanyak $15(40,5 \%)$ responden, sedangkan dalam tingkat nyeri sedang skala 4 sebanyak $1(2,7 \%)$ responden. 
Journal of Healthcare Technology and Medicine Vol. 5 No. 2 Oktober 2019

Universitas Ubudiyah Indonesia

e-ISSN : 2615-109X

\section{a. Analisa Bivariat}

Hasil sebaran data berdistribusi tidak normal dengan nilai $\mathrm{p}$ value 0,000 maka uji hipotesis menggunakan uji non parametrik yaitu uji wilcoxon atau wilcoxon's rank sum test. Analisa ini dilakukan untuk mengetahui efektivitas kompres hangat terhadap penurunan intensitas dismenorea di SMAS Inshafuddin Banda Aceh menggunakan uji wilcoxon. Hasil analisa uji wilcxocon pada penelitian ini diperlihatkan dalam tabel 4.

\section{Tabel 4}

Analisa Efektivitas Pemberian Kompres Hangat Terhadap Penurunan Intensitas Dismenorea Pada Remaja Putri di SMAS Inshafuddin Banda Aceh

\begin{tabular}{cccc}
\hline Kelompok & N & Mean & P-Value \\
\hline Pretest & 37 & 4,70 & \\
Post test & 37 & 0,70 & 0,000
\end{tabular}

Berdasarkan tabel 4 terlihat bahwa nilai rata-rata skala intensitas dismenorea sebelum diberikan kompres hangat adalah 4,70. Kemudian setelah dilakukan kompres hangat terjadi penurunan nilai rata-rata yaitu 0,70 . Hasil uji statistik didapatkan $\mathrm{P}$-value $=0,000(<\alpha 0,05)$, perbedaan tersebut secara statistik sangat bermakna, yang artinya ada efektivitas pemberian kompres hangat terhadap penurunan intensitas dismenorea pada remaja putri di SMAS Inshafuddin Banda Aceh.

Berdasarkan hasil Penelitian ini membuktikan bahwa ada perbedaan antara dismenorea sebelum pemberian terapi kompres hangat sebagian besar pada skala 4-6 (nyeri sedang) sebanyak $23(62,1 \%)$ responden dan sesudah pemberian terapi kompres hangat dismenorea sebagian besar pada skala 0 (tidak nyeri) sebanyak $21(56,8 \%)$ responden. Sesudah pemberian kompres hangat, ternyata mampu menurunkan intensitas dismenorea. Setelah dilakukan uji Wilxocon-test menggunakan program SPSS didapatkan hasil Asymp. Sig. (2-tailed) $0.000<\alpha$ $=0,05$. Hal ini menunjukkan bahwa terapi kompres hangat berdampak positif dalam menurunkan intensitas dismenorea sehingga Ha diterima, Ho ditolak dan tidak didapatkan hasil ties yang artinya tidak terjadi kesamaan sebelum dan sesudah dilakukan terapi kompres hangat.

Hasil penelitian ini didukung oleh teori Menurut Price dan Wilson (2005) Oktasari dkk., (2014) kompres hangat merupakan salah satu metode non-farmakologi yang dianggap sangat efektif dalam menurunkan nyeri atau spasme otot. Panas dapat dialirkan melalui konduksi, konveksi, dan konversi. Nyeri akibat memar, spasme otot, dan arthritis berespon baik terhadap 
Journal of Healthcare Technology and Medicine Vol. 5 No. 2 Oktober 2019 Universitas Ubudiyah Indonesia

e-ISSN : 2615-109X

peningkatan suhu karena dapat melebarkan pembuluh darah dan meningkatkan aliran darah lokal. Oleh karena itu, peningkatan suhu yang disalurkan melalui kompres hangat dapat meredakan nyeri dismenorea.

Sejalan dengan penelitian Restyana (2017) tentang pengaruh kompres hangat terhadap penurunan intensitas dismenorea bahwa sudah dilakukan uji Wilcoxon didapatkan hasil Asymp.sig. (2-tailed) 0,00 0,05 maka hal ini menunjukkan Ha di terima yang berarti ada hubungan kompres hangat dengan penurunan intensitas dismenorea.

Sesuai juga dengan penelitian Dwi Riani (2017) tentang pengaruh kompres hangat terhadap penurunan nyeri dismenorea bahwa sudah dilakukan uji Wilcoxon didapatkan hasil Asymp.sig. (2-tailed) 0,002 0,05 maka hal ini menunjukkan Ha di terima yang berarti ada terdapat pengaruh kompres hangat dengan penurunan nyeri dismenorea.

Menurut peneliti, skala intensitas dismenorea sebelum diberikan terapi kompres hangat adalah skala nyeri sedang. Hal ini di karenakan siswi tinggal di asrama mengalami banyak tekanan sehingga mengakibatkan stres, kecapean, kurang istirahat, kurangnya asupan makanan yang mengandung tinggi nutrisi dan mineral, dan kurangnnya melakukan aktifitas seperti olahraga. Untuk itu maka perlu dilakukan kompres hangat karena dapat mengurangi nyeri, dan dapat mengurangi penggunaan obat-obatan, selain itu kompres hangat juga mudah diterapkan dan ekonomis.

Hasil penelitian sesudah mendapatkan perlakuan kompres hangat didapatkan hasil skala nyeri menstruasi menurun. Hal ini dikarenakan dari 37 responden, peneliti memberikan terapi kompres hangat sesuai dengan SOP (Standart Operasional Prosedur).

Penurunan intensitas dismenorea bisa disebabkan karena adanya perpindahan panas secara konduksi dari alat WWZ yang berisi air hangat ke dalam perut yang melancarkan sirkulasi darah dan menurunkan ketegangan otot sehingga menurunkan intensitas dismenorea.

Hal ini dapat terlihat pada hasil penelitian yang menunjukkan bahwa sebelum dilakukan perlakuan terapi kompres hangat banyak siswi yang berada pada skala nyeri sedang dan sesudah dilakukan terapi kompres hangat terjadi penurunan yang banyak berada pada skala tidak nyeri. Kompres hangat sangat efektif dilakukan untuk mengurangi intensitas dismenorea karena tidak memerlukan biaya yang banyak, waktu yang lama, dan kerja fisik yang berat tetapi harus tetap hati-hati karena air yang terlalu panas dapat mengakibatkan iritasi pada kulit. 
Journal of Healthcare Technology and Medicine Vol. 5 No. 2 Oktober 2019

Universitas Ubudiyah Indonesia

e-ISSN : 2615-109X

\section{KESIMPULAN}

Berdasarkan hasil penelitian tentang pengaruh pemberian kompres hangat terhadap penurunan intensitas nyeri dismenorea pada remaja putri di SMAS Inshafuddi Banda Aceh maka dapat di simpulkan bahwa: dari 37 responden sebelum diberikan kompres hangat intensitas nyeri responden dalam skala 4,70, sesudah dilakukan kompres hangat terdapat penurunan intensitas nyeri responden dalam skala 0,70, dan terdapat efektivitas pemberian kompres air hangat terhadap penurunan intensitas nyeri dismenorea pada remaja putri SMAS Inshafuddin Banda Aceh. Berdasarkan hasil uji wilcoxon yaitu dengan nilai Asymp Sig. $(2$ tailed $)=0,000(<0,05)$.

\section{SARAN}

Diharapkan kepada remaja putri agar dapat menambah ilmu dan wawasan tentang terapi kompres hangat untuk menurunkan intensitas nyeri dismenorea. Diharapkan bagi petugas kesehatan dapat memberikan penyuluhan untuk meningkatkan pengetahuan tentang dismenorea pada remaja putri dan meningkatkan derajat kesehatan ke arah yang lebih baik. Bentuk-bentuk program yang dapat dilakukan secara berkesinambungan seperti penyuluhan kesehatan, pembimbingan dan pembinaan, pelatihan di sekolah-sekolah yang terdapat remaja putri agar mereka bisa mengantisipasi sejak dini bila terjadi dismenorea.

\section{DAFTAR PUSTAKA}

Anurogo, D. (2011). Catatan Kuliah Ginekologi dan Obstetri (Obgyn) untuk Keperawatan dan Kebidanan. Yogyakarta: Nuha Medika.

Anis Rofoqoh (2017) Pengaruh Pemberian Kompres Air Hangat Terhadap Penurunan Intensitas Nyeri Dysmenorrhea Pada Mahasiswi. skripsi Stikes Jenderal Achmad Yani Yogyakarta akses http://repository.unjaya.ac.id/2234/2/ANIS\%20ROFIQOH 2213079 pisah.pdf.01 november 2018.

Apay, S. E., Arslan, S., Akpinar, R. B., dan Celebioglu, A. (2012). Effect of Aromatherapy Massage on Dysmenorrhea in Turkish Students. American Society for Pain Management Nursing. Department of Midwifery, Faculty of Health Sciences, Atatürk University, Erzurum, Turkey. https://www.painmanagementnursing.org/article/S1524-9042(10)00067-6/fulltext DOI: https://doi.org/10.1016/j.pmn.2010.04.002 November 01, 2018.

Asmadi. (2010). Teknik Prosedural Keperawatan: konsep dan Aplikasi Kebutuhan Dasar Klien, Salemba Medika, Jakarta, Indonesia.

Arikunto,S. (2010). Proseur penelitian, Edisi revisi 2010, Rineka Cipta, Jakarta, Indonesia

Bharthi, H.P., Murthy, S.N., Babina, N., Kadam, A., Rao, R. (2012). Management Of Pelvic Pain in Primary Dysmenorrhea Using a Hot Hip bath: A Pilot 
Study. https://search.proquest.com/openview/c7c71278c02f8f8424c9214475c4f6ec/ 1 ?pq-origsite $=$ gscholar\&cbl $=32528$ diakses November 01,2018.

BKKBN. (2018). Keluarga Berencana dan Kesehatan Reproduksi. Jakarta: BKKBN.

Dermawan, D \& Jamil, A.M. (2013). Keterampilan Dasar Keperawatan Konsep dan Prosedur, Buku 2, Gosyen Publising, Yogyakarta, Indonesia.

Diyan, Indriani. (2013). Keperawatan Maternitas Pada Area Perawatan Antenatal. Yogyakarta: Graha Ilmu.

Dwi Riani. (2017). Pengaruh Kompres Hangat Terhadap Penurunan Nyeri Dismenorea Pada Mahasiswi, skripsi Universitas 'Aisyiyah Yogyakarta di akses http://digilib.unisayogya.ac.id/2690/1/DWI\%20RIANI\%201610104420_N ASKAH\%20PUBLIKASI.pdf 01 november 2018.

Ema, Hewari. (2010). Manajemen Stress Cemas dan Depresi. Jakarta : FKUI.

Ganong, William F. (2010). Buku Ajar Fisiologi Kedokteran. Jakarta : EGC.

Hartono.(2010). Stress dan Diemenore. http:// Indonesiaindonesia.com/ diakses tanggal 6 November 2018.

Hidayat \& Uliyah. (2011). Praktikum keterampilan dasar praktik klinik: Aplikasi dasar-dasar praktik kebidanan, Salemba Medika, Jakarta,Indonesia.

Manuaba, I.B.G. (2010). Konsep Obstetri \& Gynekologi Sosial Indonesia. Jakarta: EGC.

Merdianita, Vonny. dkk. (2013). Efektivitas Kompres Hangat Dalam Menurunkan intensitas Nyeri Dysmenorrhoea Pada Mahasiswa STIKES RS Baptis Kediri. Jurnal STIKES RS Baptis Kediri 6 (1). 1-10.

Nasution. (2012). Merokok Pada Remaja Masa Kini. http://infokes.blogspot.com/ diakses tanggal 6 november 2018.

Notoatmodjo. (2013). Metodologi Penelitian Kesehatan. Jakarta: PT Rineka Cipta.

Notoatmodjo. (2012). Metodologi Penelitian Kesehatan. Jakarta: PT Rineka Cipta.

Nugraha, M. (2011). Perawatan Kebidanan dan Kesehatan Reproduksi. Medan :Gramiko Pustaka Raya.

Nugroho. T \& Utama. B. I. (2014). Masalah Kesehatan Reproduksi Wanita. Nuha Medika, Yogyakarta, Indonesia.

Nursalam.(2013). Konsep Dan Penerapan Metodelogi Penelitian Ilmu Keperawatan,Edisi 3,Salemba Medika, Jakarta,Indonesia.

Oktasari, G.; Misrawati \& Utami, G. T. (2014). 'Perbandingan Efektivitas Kompres Hangat dan Kompres Dingin Terhadap Penurunan Dismenorea Pada Remaja Putri'. Skripsi, Sarjana Keperawatan, Universitas Riau, Riau.Diakses 01 november 2018.

Prawirohardjo, Sarwono. (2007). Ilmu Kandungan. Jakarta : YBP-Sp.

Prawirohardjo, Sarwono. (2010). Ilmu Kandungan. Jakarta : YBP-Sp.

Potter \& Perry. (2010). Buku Ajar Fundamental Keperawatan. Buku 3. Edisi 7. Alih bahasa inggris-bahasa indonesia, Yasmin, dkk, Elsevier pte ltd, Singapore.

Rahayu, (2010). Perkembangan Anak Dan Remaja. Jakarta: Rineka Cipta.

Restyana,saras.w (2017) Pengaruh Pemberian Kompres Hangat Terhadap Penurunan Nyeri Menstruasi (Dysmenorrhea) Pada siswi kelas VII. skripsi Stikes Jenderal Achmad Yani Yogyakarta di akses http://repository.stikes-bhm.ac.id/231/1/64.pdf 01 november 2018.

Sornim, N. M. (2014). Efektivitas Senam Dysmenorrhea Dalam Mengurangi Dysmenorrhea Pada Remaja Putri Di SMP Negri Siantan Kabupaten Pontianak. Skripsi. Universitas Tanjungpura. Pontianak. Diakses http://jurnal.untan.ac.id/index.php/jmkeperawatanFK/article/view/6480 November 012018.

Sugiyono. (2016). Statistik Untuk Penelitian, Alfabeta, Bandung, Indonesia. 
Journal of Healthcare Technology and Medicine Vol. 5 No. 2 Oktober 2019

Universitas Ubudiyah Indonesia

e-ISSN : 2615-109X

Siregar, S. (2013). Statistik Parametrik untuk penelitian kuantitatf. Dilengkapi dengan perhitungan manul dan aplikasi SPSS versi 17, PT Bumi Aksara, Jakarta, Indonesia.

Taber, Ben-zion, M.D. (2011). Kapita Selekta Kedaruratan Observasi dan Ginekologi. Jakarta : EGC

Tiran, Denise. (2012). Kamus Saku Bidan. Jakarta : EGC

Zahradnik. H. P., Beck. A. H., Groth. K. (2010). Nonsteroidal Ant-Inflammatory Drugs and Hormonal Contraceptives For Pain Relief From Dysmenorrhea: a review. Clinic for Endocrinology and

Reproductive

Medicine,University Hospital Freiburg, Freiburg, Germany. https://www.ncbi.nlm.ni h.gov/pubmed/20159173 DOI: 10.1016/j.contraception.2009.09.014. 
Journal of Healthcare Technology and Medicine Vol. 5 No. 2 Oktober 2019

Universitas Ubudiyah Indonesia

e-ISSN : 2615-109X 